\title{
Examining Gender Differences in Students' Entrance into and Persistence in STEM Programs in Swedish Higher Education
}

\author{
Shu-Nu Chang Rundgren ${ }^{4}$ \\ Professor, Department of Education at Stockholm University, \\ Stockholm, Sweden \\ Yu-ling Sun \\ Master student, Department of Education at Stockholm University, \\ Stockholm, Sweden \\ Anders Jidesjö \\ Assistant Lecture, Department of Thematic Studies, \\ Linköping University, Linköping, Sweden
}

\begin{abstract}
Encouraging students to enter and persist in science, technology, engineering and mathematics (STEM) programs in higher education has been the focus of STEM education worldwide. To promote social equality particular attention has been given to including student groups such as women, ethnic minorities, and students with low economic status that have long been underrepresented in STEM education. The aim of this research was to examine gender differences in students' entrance into and persistence in STEM programs in Swedish higher education through the lens of social cognitive career theory (SCCT). Through a quantitative secondary analysis of Interest and Recruitment in Science (IRIS) project data collected in Sweden, a total of 2372 responses were validated and analyzed, including 1530 males (65\%) and 842 females (35\%). The main findings showed that female students valued previous learning experiences in formal education contexts and social influences more than males, with a significant difference of $(p<0.05)$. Male students valued informal learning experiences more and presented selfefficacy and choice goals to a higher degree, with a significant difference of $(p<0.05)$. No significant gender differences were found with regard to appreciation of current study life. The discussions and implications of the findings and previous research are presented.
\end{abstract}

4 Corresponding author 
Keywords: STEM education; Gender; Higher education; entrance; persistence.

\section{Introduction}

Combinations of attitudes, knowledge and skills in science, technology, engineering and mathematics (STEM) have been considered critical competencies in the knowledge economy. On a national scale, STEM fields have been recognized by the U.S. government as "areas of national need" that are "crucial to national innovation, competitiveness, and wellbeing" (Goan et al. 2006, p. 1). Similarly, the European Commission incorporated key competencies such as "mathematical competence and basic competencies in science and technology" and "digital competence" as key objectives for the reference framework for lifelong learning in European countries' national curricula (European Commission 2018). At the individual level, STEM education not only prepares individuals with competencies for problem solving and innovation in their daily lives, but also actively involves them in solving complex challenges faced by their societies with critical and creative thinking (Hazelkorn et al. 2015). The implications for STEM educational policies around the world lie not only in promoting scientific literacy among citizens, but also in attracting people to participate in STEM disciplines in secondary and higher education, and further to pursue STEMrelated professions and/or research-scientific careers for international competition (Hazelkorn et al. 2015; Laugksch 2000).

Despite the fact that the numbers of students pursuing higher education degrees have been increasing, the percentage of students in STEM disciplines remains relatively low. The shortage of students pursuing STEM disciplines has been recognized globally. In Europe, it has been pointed out that one million additional researchers are needed in STEM studies by 2020 to sustain economic growth (Hazelkorn et al. 2015). On the other hand, many students view studying STEM in higher education as a pathway to careers that are not directly related to STEM disciplines. For example, many students in the U.S. view majoring in biology or chemistry as a way to become medical doctors rather than biologists or chemists. Some students see mathematics and science as their stepping-stones to the worlds of business, finance or entrepreneurship. Engineering studies sometimes provide backgrounds for students aspiring to careers as patent lawyers (Sadler et al. 2012). As a country considered being among the foremost when it comes to gender equality (UNDP 2015), Sweden has broadened the educational pathway for more students to engage in higher education. Specifically in STEM education, completing the natural science program in upper secondary school is regarded as the ideal way to prepare for a STEM field of study in higher education in Sweden (Skolverket 2000). However, despite abundant opportunities for entering STEM disciplines and 
the government's flexible combination of grants and loans for financial support in Swedish higher education (Langen and Dekkers 2005), only 25\% of 25-34 year-olds chose to participate in STEM disciplines in year 2016 (OECD 2017). According to OECD statistics for year 2015, only 38\% of total enrollment and $22 \%$ of STEM higher education graduates are women (OECD.Stat n.d.). Although gender equality and equal treatment for men and women have been actively promoted in Sweden for decades, gender disparities in STEM course participation persist. To understand the gender gap in STEM education and careers, it is important to investigate how students' academic and career choices developed over time, and the crucial factors that have both direct and mediating effects on their decision-making. Understanding what factors drive students of both genders to step onto the STEM pathway and whether they remain on it can help educators and policy makers identify more efficient ways of encouraging students to enter the STEM domain and keep them there.

Early attitudes developed in adolescence play a fundamental role in determining students' aspirations for future careers (Ormerod and Duckworth 1975; Tai et al. 2006; Lindahl 2007; as cited in DeWitt et al. 2011). By the age of 13 or 14, most students' attitudes towards science are well established and become progressively harder to change (DeWitt et al. 2011). Thus, secondary education is regarded as a critical period in attaining and developing students' interest in STEM disciplines so that they will choose to study STEM-related majors in higher education. After students enroll in STEM majors, their interests then influence their retention. Students may subsequently drop out due to a lack of interest in STEM, concern over the occupational lifestyle, or a growing interest in other disciplines (Heilbronner 2011). On the other hand, related learning experiences in STEM are believed to contribute to the development of self-efficacy beliefs that indicate individuals' confidence in studying mathematics and science subjects. Students' self-efficacy beliefs further influence their interests, behavior, and intention to enter or persist with STEM disciplines. Bloom (1985) investigated high-achieving individuals in neuroscience to uncover factors that influenced their choice of career. He discovered that for many the learning experience of setting up their own experiments and investigations, and enjoyment of exploring what they could discover, helped them build a strong interest in science from a young age (as cited in Sosniak 1985). However, STEM-related learning experiences are influenced by many environmental factors, such as the economic, social and cultural capitals that specifically relate to science. Financial security and social prestige also influence students' choices of desirable professions (Wong 2012). DeWitt and Archer (2015) emphasize that a social connection to science, such as having family members working in science, is seen as particularly important for female students or students from ethnic minority 
groups. Positive attitudes towards science and encouragement during the academic process from important social relations such as parents and peers can influence students' own attitudes and interest in science and inspire them to pursue STEM careers.

Accordingly, the aim of this research is to investigate important learning experiences, the self-efficacy beliefs and choice goals that relate male and female first-year STEM students' entrance into and persistence in STEM studies in Swedish higher education, based on a secondary analysis of an EU project, Interest and Recruitment in Science (IRIS). The specific research questions are:

- Are there any differences between male and female students relating to previous learning experiences that were important factors in choosing their current majors?

- Are there any differences between male and female students' responses regarding their current learning experiences?

- Are there any differences between male and female students' selfefficacy beliefs and choice goals?

\section{Literature Review}

Students' academic choices related to STEM education have gained increasing scholarly attention in the last decade. Numerous studies have explored critical contextual, cultural and cognitive factors influencing students' entrance into, persistence in and completion of STEM disciplines (e.g., Wang 2013; Byars-Winston et al. 2010; Lent et al. 2008). Following, in relation to the study, we explore the main factors including self-efficacy and learning experiences, as well as external social and environmental factors that are identified in previous studies as promoting or impeding students' academic choices in STEM.

\section{Self-efficacy and Outcome expectations in STEM}

Self-efficacy beliefs are considered to constitute the most central and pervasive mechanism of personal agency that helps individuals to determine their choices of activities and environments (Bandura 1986). Self-efficacy beliefs also contribute to effort expenditure, persistence, thought patterns and emotional reactions when confronted by obstacles (Lent et al. 1994). Outcome expectations are another important factor that influences individuals' behavior intentions. Studies of self-efficacy are either further specified in specific STEM subjects like math, science and engineering, or are combined as general academic self-efficacy. Lopez and Lent (1992) investigated 50 high school students' sources of math self-efficacy beliefs. They applied the sources of math efficacy scale (SMES), originally developed by Lent et al. (1991), to 
capture the students' four primary sources of self-efficacy beliefs as described by Bandura (1986).

\section{Learning Experiences Relate to STEM}

Related learning experiences in STEM are believed to contribute to the development of interests in STEM disciplines. When examining students' entrance into STEM, various studies point out that high school preparation in math and science plays a critical role in developing students' interests in STEM studies (e.g., Wang 2013; Blickenstaff 2005; Maltese and Tai 2011). As Blickenstaff (2005) points out, selection and completion of math and science courses during high school were essential in developing students' predispositions toward choosing STEM studies at post-secondary level. Also, students who perceive their high school math and science courses to have adequately prepared them for college are likely to choose a STEM major (Wang 2013). A more rigorous high school program is considered significant in students' attainment of college degrees (Maltese and Tai 2011). Regarding gender differences in high school course participation, Tyson et al. (2007) found that women completed more advanced coursework than their male peers, but were less likely to complete the highest-level courses (i.e., advanced physics or calculus). However, the identification of learning experiences varies with difference approaches.

Learning experiences outside of classrooms are recognized as opportunities for young people that complement and extend beyond the resources available in school (DeWitt and Archer 2017). DeWitt and Archer (2017) identify three types of science education engagement outside of the classroom. School-led science enrichment includes taking science-related school trips, attending presentations about science or after-school science clubs; 'informal' science activities concerns visiting zoos, doing experiments, and going to science centers or museums; 'everyday' science engagement includes watching science programs on TV, reading science books, or going online to find out about science. Science and math education can happen in diverse contexts - not only from pedagogical interventions in school - but also in casual, spontaneous, non-structured places in informal settings (Kim and Dopico 2016). However, it has been shown that the participation of children in informal science learning and how much they gain from it are not only driven by their own interests in the activities, but also fundamentally shaped by physical (activity location), economic (associated costs), social (support from important family members), and cultural factors as well as their science capital (DeWitt and Archer 2017). The combination of these factors can either open up or shut down children's access to and participation in science education in informal settings. 
Lent et al. (1994) proposed social cognitive career theory as a sociocognitive approach to people's interests and academic/career choices. Developed from Bandura's (1986) social cognitive theory, social cognitive career theory emphasizes not only the means by which individuals exercise personal agency in the academic choice and career development process, but also the extra factors enhancing or constraining personal agency (Lent et al. 1994). In particular, learning experiences have been described by Lent et al. (1994) as directly informing and shaping academic and career-related selfefficacy. Lent and colleagues $(1994,2000)$ posited that learning experiences do not occur in isolation. They are under the influence of contextual variables, either distal background factors preceding learning experiences such as gender, race and socioeconomic status, or proximal factors playing a role at critical choice points such as peers and teachers (Ferry et al. 2000).

\section{Contextual Factors Influencing Learning Experiences}

Contextual factors such as one's cultural, social and economic background are considered to have direct impact on one's learning experiences. Analysis by DeWitt and Archer (2015) revealed structural factors including gender and it was discussed that ethnicity and cultural capital strongly influence students' attitudes, experience and participation of science in school and out of school. Archer et al. (2014) define science capital as a conceptual device that combines various types of economic, social and cultural capital that specifically relate to science. Wong (2015) points out that these resources related to science learning could strengthen or weaken students' interests towards, and identifications with, science and science careers. Having family members using science in their work is particularly important for students in ethnic minority groups to aspire to a science career. Results from DeWitt and Archer (2015) showed that students who have a family member working in a science-related job are 2.16 times more likely to fall into the group that strongly aspired to a science career than those who do not.

Wang (2013) identifies several aspects of a postsecondary context of supports and barriers including academic interaction, receipt of financial aid, enrollment intensity, graduate degree expectations, remediation, and external demands. Among these, academic interaction was measured by how frequently students interact with faculty about academic matters, meeting with advisors about academic plans, and studying in school libraries. Receipt of financial aid was regarded as a dichotomous variable based on students' firstyear aid status. Enrollment intensity was examined by asking whether students' enrollment was full-time or part-time. In addition, students' graduate degree expectations were divided into whether students expected to earn a graduate degree or not (Wang 2013). 


\section{Theoretical Framework: Social Cognitive Career Theory}

This study aims to analyze and compare learning experiences that are perceived by male and female students to be important to their entrance into and persistence in STEM programs, as well as their self-efficacy beliefs and future educational choice goals. The focus is on the complex interplay of person, environment, and behaviors leading to people's interests and academic/career choices. Social cognitive career theory (SCCT), proposed by Lent, Brown, and Hackett (1994), provides a useful theoretical framework for the study. Derived primarily from Bandura's (1986) general social cognitive theory, SCCT closely explores Bandura's (1986) concepts, including selfefficacy, outcome expectations, and goal mechanisms, and the complex interrelating systems of these concepts with other personal (e.g., gender, race), contextual (e.g., support systems), and experiential/learning factors (Lent et al. 1994). Concerning the application of SCCT Choice Model in the Study, Figure 1 shows how the choice model of SCCT is incorporated in the context of this study. Specifically, SCCT's choice model provides an explanatory theoretical framework to understand how students' academic and career related choices are developed over time. Participants in this study were students studying STEM majors at first-year university level. The first half of the theoretical framework examined students' 'pre-higher educational settings' experiences, such as the formal and informal learning experiences and social influences, which encouraged them to choose their current majors. The second half of the framework investigated students' perceived current 'higher education' learning experiences as well as their self-efficacy beliefs and choice goals. SCCT was applied to enable discussion about how students perceived their current learning experiences to be influenced by, for example, their social relations with peers and teachers, which further impact students' self-efficacy beliefs and intentions about persisting in STEM programs.

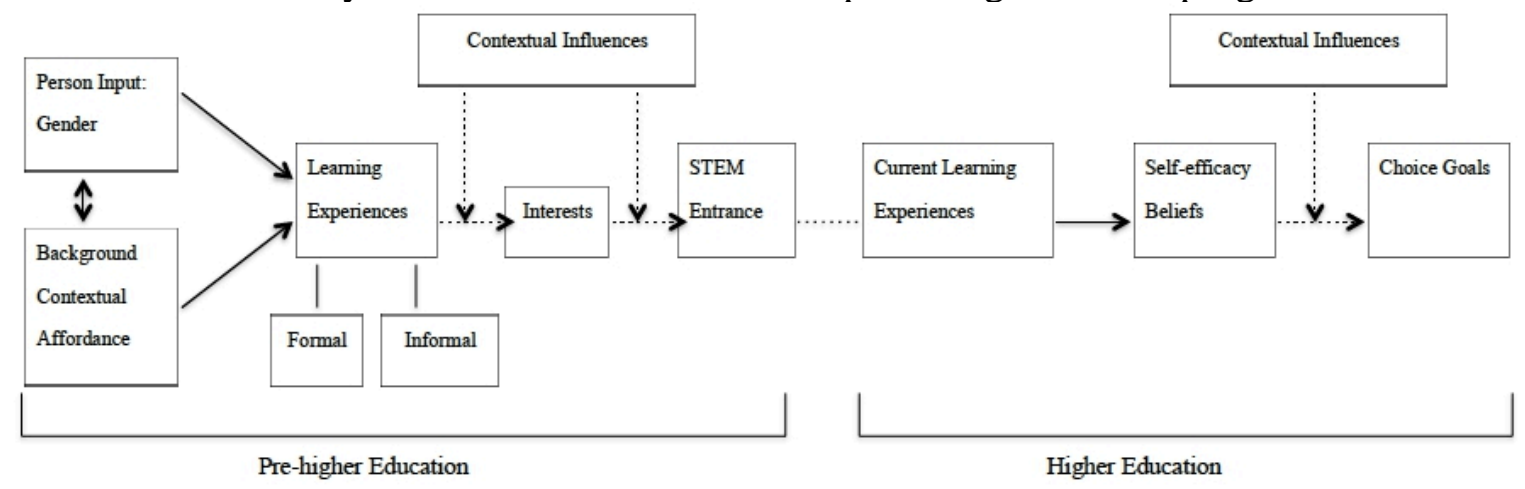

Figure 1. Application of SCCT choice model to the study

In Figure 1, solid lines indicate direct influence while dotted lines demonstrate moderate influence between two constructs. Gender is regarded 
as a person input and has a reciprocal relation to background contextual affordance such as socioeconomic status. These two elements directly influence one's learning experiences during secondary education, including formal learning experiences and informal learning experiences. Learning experiences indirectly impact on one's interest in STEM disciplines through self-efficacy beliefs and outcome expectations, which further influences one's decision about entering a STEM major. At the same time, contextual factors such as the supports and barriers the student experiences have a mediating effect on his/her decision-making process. After enrolling in STEM majors, the student perceives current learning experiences (including his/her evaluation of the learning experiences), and comparison with his/her expectation, to directly influence his/her self-efficacy beliefs about their ability to study a specific subject. His/her self-efficacy beliefs, interests, and outcome expectations have an indirect impact on the choice goals about whether to engage further in the course of study.

Contextual influences mediate students' choices about enrolling in STEM programs in higher education and persisting with STEM studies. The study primarily examined students' perceived contextual influences such as the importance of learning experiences and social connections. Due to the design of the IRIS questionnaire, the study did not distinguish distal and proximal environmental factors when discussing contextual influence. Namely, this study applied the term "pre-higher education" to describe the timeline of previous learning experiences in the questionnaire. In the prehigher education environment, contextual influences may encourage or hinder the development of students' self-efficacy beliefs and interest in science and mathematics. This includes social and family cultures regarding gender stereotypes and the culture/environment of science/math classrooms. In higher educational settings, contextual influences mediate students' persistence with chosen STEM subjects. Friendly or hostile peer/teacher environments within current programs, perceived obstacles, and external opportunities or support all influence decisions about whether to leave or stay in the program.

\section{Methods}

\section{Research Strategy}

This study applied a quantitative research strategy for a secondary analysis of collected responses to the Interest and Recruitment in Science (IRIS) questionnaire in Sweden. Bryman (2016) points out that secondary analysis entails the analysis of existing data that the researchers probably have not been involved in collecting. This secondary analysis was attempting to offer new interpretations of the Swedish IRIS data from the theoretical framework of SCCT. Specifically, this study aims to discover the significant gender differences in (1) the important previous learning experiences in pre- 
higher education that affect students' entrance into STEM programs, (2) important current learning experiences while studying STEM programs in higher education, and (3) self-efficacy beliefs, positive and negative goals for persisting with STEM programs.

\section{Research Instrument}

As the content of secondary analysis, this study explored the Swedish students' responses to the questionnaire designed in the IRIS project, which has been conducted in many countries, including Sweden. Nearly 7000 firstyear university students studying STEM disciplines in Norway, the United Kingdom, Slovenia, Italy, and Denmark completed the IRIS questionnaire during year 2010-2011 (IRIS 2012). Since then, the IRIS questionnaire has been administered in other countries such as Sweden to examine students' interest in and recruitment into STEM programs. The IRIS questionnaire comprises 17 questions examining previous school experiences, sources of inspiration for educational choice, current experiences as a first-year STEM student, expectations for future jobs, and attitudes to gender equity in STEM studies (IRIS 2012). Apart from the first five questions about participants' basic information, the remaining 12 questions consist of 8 Likert-scale questions comprising 65 Likert-type items and 4 open-ended questions.

Likert-scale questions in the IRIS questionnaire generally offer a fivepoint scale ranging from "Not important" to "Very important" and "Strongly disagree" to "Strongly agree". Only one question offered a three-point Likert scale labeled "worse than expected", "as expected" and "better than expected" (question 11). In this study, six Likert-scale questions were selected for analysis according to their relevance to the aim of the study.

\section{Participants and Data collection}

According to IRIS project working document 2.2 (2010), the target population of the IRIS project was students toward the end of their first year of study in a limited number of STEM courses at higher education level. Criteria include:

- central or typical STEM education/subject;

- general recruitment challenge;

- gender imbalance;

- easy to identify corresponding education/program across countries;

- well-defined education/program (not cross-discipline programs such as "technology, organization and learning"); and

- preferably large numbers of students in a small number of institutions/programs (to facilitate sampling and administration) (IRIS 2010). 
Following the general guideline of the IRIS project, the target population for this study was first-year university students studying STEM courses in 10 different Swedish universities during the data collection period. The majority of students were born in the 1990s. Nearly one third of students had experiences of studying at other universities (Jidesjö et al. 2015). The original version of the IRIS questionnaire is in English, and it was translated into Swedish following the IRIS project back-translation procedure (IRIS 2010). The IRIS questionnaire was in electronic format and was sent out to over 10000 students via email. After excluding invalid responses, and selecting responses based on consent and convenience, a total number of 2372 responses were selected, with 1530 males (65\%) and 842 females (35\%).

\section{Data Analysis}

Based on the comparative lens of gender perspective, "female" was coded as " 0 " and "male" was coded as " 1 " when analyzing the data. For question numbers $6,7,8,10$, and 12 that used a five-point Likert scale, scores 1-5 were coded to measure participants' responses from "Not important" to "Very important"; and to responses from "Strongly disagree" to "Strongly agree". For question number 11, which used a three-point Likert scale, scores 1-3 were coded to measure students' responses among "worse than expected", "as expected", and "better than expected". The item concerning "the effort you have to spend on studying" in question 11, and the item "I will probably decide to leave this course before I finish" in question 12, were both negatively worded questions compared to the other positively worded questions. Therefore, reverse scoring was applied to these two items. Descriptive analysis was conducted to demonstrate the mean scores and standard deviations of all six Likert scale questions via Statistical Program for the Social Sciences (SPSS) version 25. To compare the difference between two gender groups, a non-parametric technique was adopted for several reasons. First, samples were selected for convenience (non-random sampling) so data did not follow normal distribution. Secondly, samples obtained from populations were not of equal variance because two group sizes were not reasonably similar. The ratio of largest group size to smallest group size was larger than 1.5 and thus violated the assumption of homogeneity of variance in the parametric technique (Stevens 1996, as cited in Pallant 2016). The Mann-Whitney U test was used (Lared statistics n.d.) in this study to determine whether there were significant differences between the mean scores of formal learning experiences, social influence, informal learning experiences, current learning experiences, current learning experiences compared to expectations, selfefficacy beliefs, and choice goals. Statistically significant difference between two gender groups, if $\mathrm{p}<0.05$. 


\section{Quality Criteria of the Study}

Reliability, validity and replicability are viewed as three of the most critical criteria for evaluating the quality of quantitative social research (Bryman 2016). The Cronbach's alpha for internal reliability of the Swedish IRIS questionnaire response data was 0.83 , which demonstrates good internal reliability. Validity is about whether a set of indicators devised from a concept really measures the concept (Bryman 2016). The IRIS questionnaire addresses important factors that influence students' educational choice making in STEM, and is based on the achievement-related choices model proposed by Eccles et al. (1999) and Bandura's theories on the role of self-efficacy beliefs (Bandura 1997; as cited in Elster 2004). The theoretical framework of the secondary analysis on the IRIS responses data was Social Cognitive Career Theory developed by Lent et al. (1994), which was derived from Bandura's (1986) theories on self-efficacy beliefs. The external validity deals with the generalization of findings, which concerns the representativeness of samples (Bryman 2016). Convenient sampling has been applied in the collection of the Swedish IRIS data though online surveys that yielded an approximately 2025\% response rate. Mandreda et al. (2008) point out that the response rate of online surveys is on average $11 \%$ lower than that of other modes of sampling such as postal questionnaire surveys (as cited in Bryman 2016). However, as Bryman (2016) states that it is the absolute size of a sample that is important relating to the degree of its precision. This study analyzed usable responses from a sufficiently representative sample of 2372 STEM students in higher education in Sweden.

We may assume the replicability of the study, given that, as at January 2014, the IRIS questionnaire had been administered in at least 15 countries, in addition to the five comprising the IRIS consortium (Henriksen et al. 2014). In early 2010, a pilot study of the IRIS questionnaire was administered in various formats, including electronic media, pencil and paper, and focus group discussions (Henriksen et al. 2014). After finalizing the master version of the IRIS questionnaire in English, translation into other languages followed a standardized, quality-assured procedure (Henriksen et al. 2014).

\section{Ethical Considerations}

This project (IRIS project number 230043) strictly observed the ethical assurance procedures as set out in the EU FP7 Collaborative Project grant agreement. The collection of IRIS data in Sweden followed the general IRIS program framework (2008) and the ethical guidelines of the Swedish research council. Students who wished to remain anonymous did not give contact details. Personal information and responses have been kept strictly confidential; no participant will in any way be recognized in any publication through the project. 


\section{Limitations of the Study}

As pointed out by Bryman (2016), one limitation of conducting secondary analysis is lack of familiarity with and control over the structure and contours of the data. In this study, the IRIS questionnaire has already been designed on the basis of the original theoretical frameworks and administered in multiple countries. Thus when attempting a secondary analysis on the original data from another theoretical perspective, some key variables may be absent. For example, the IRIS questionnaire did not include students' expected outcomes of studying STEM majors. However, this study has no intention to investigate relational or causal paths among all variables based on the applied theoretical framework. Instead, this study used the theoretical framework as a guideline and explanatory framework among all variables. Namely, variables that are missing in the theories will not have an impact on the quality or the practical implications of this study. Another limitation is the data collection period, which spanned the years 2010 through 2012, so the findings cannot mirror the current situation today. However, it may be worthwhile for researchers in higher education to consider these findings and plan for subsequent surveys in the context of a longitudinal study.

\section{Results}

\section{Previous Learning Experiences}

The first research question examined students' previous learning experiences that they perceived to be important in choosing their current STEM programs. The examination comprised three aspects of experiences, including social influences in both formal and informal educational learning settings. Both male and female students emphasized the important influence of formal learning experiences on their academic choices and played down the influence of informal learning experiences. As shown in Figure 2, a significant gender difference was found in all three aspects $(p<0.05)$. Female students considered formal learning experiences and social influences more important influencers than the male students did. On the other hand, male students considered learning in informal settings more important for them than did the female students. 


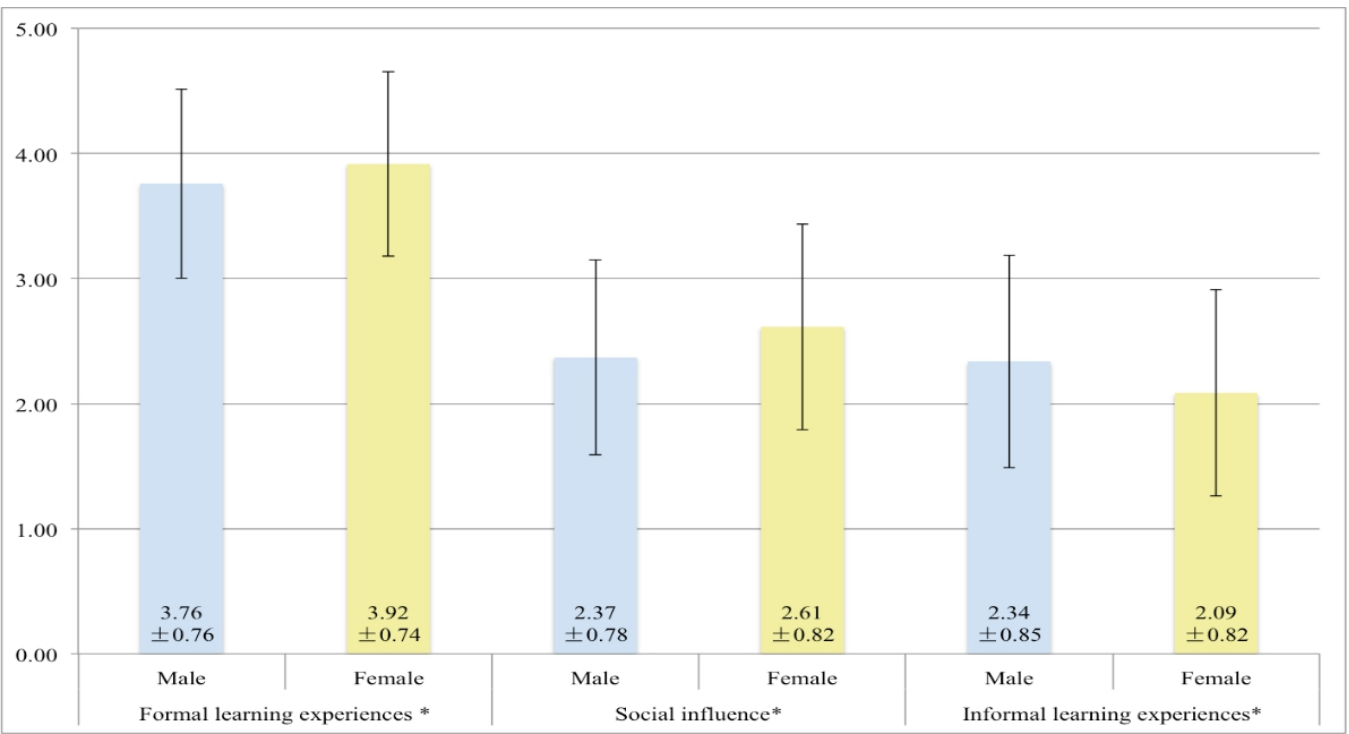

Figure 2. Results of previous learning experiences $(*, p<0.05)$.

\section{Formal learning experiences}

Looking at specific experiences in formal educational settings, interests were regarded as the most important factor in choosing their current majors, while both male and female students considered fieldwork or excursions the least important. A significant gender difference was found in the perceived importance of previous attainment, fieldwork or excursions, lesson content showing the relevance of the subject to society, and receiving clear feedback when getting the right answers $(p<0.05)$. As shown in Figure 3 , the female students regarded previous attainment as more important than did the males. Female students regarded fieldwork or excursions as more important than did their male peers. The female students considered lesson content connecting to the relevance of the subject to society more important for them than the males did. Lastly, female students valued the importance of receiving clear feedback when getting the right answer more than the males.

\section{Social influence}

Both male and female students regarded having good teachers as the most important social influence on their academic choice. The second and third most important social connections were father/step-father and mother/step-mother, followed by the influence of friends and siblings or other relatives. The importance of career advisors at school was considered the least important for both sexes. Significant gender differences were found in the social influence of mothers or step-mothers, fathers or step-fathers, good teachers, friends, other relatives and career advisors $(p<0.05)$. With mean scores and standard deviations shown in Figure 4, the female students 
considered all sources of social influence more important for them than the male students.

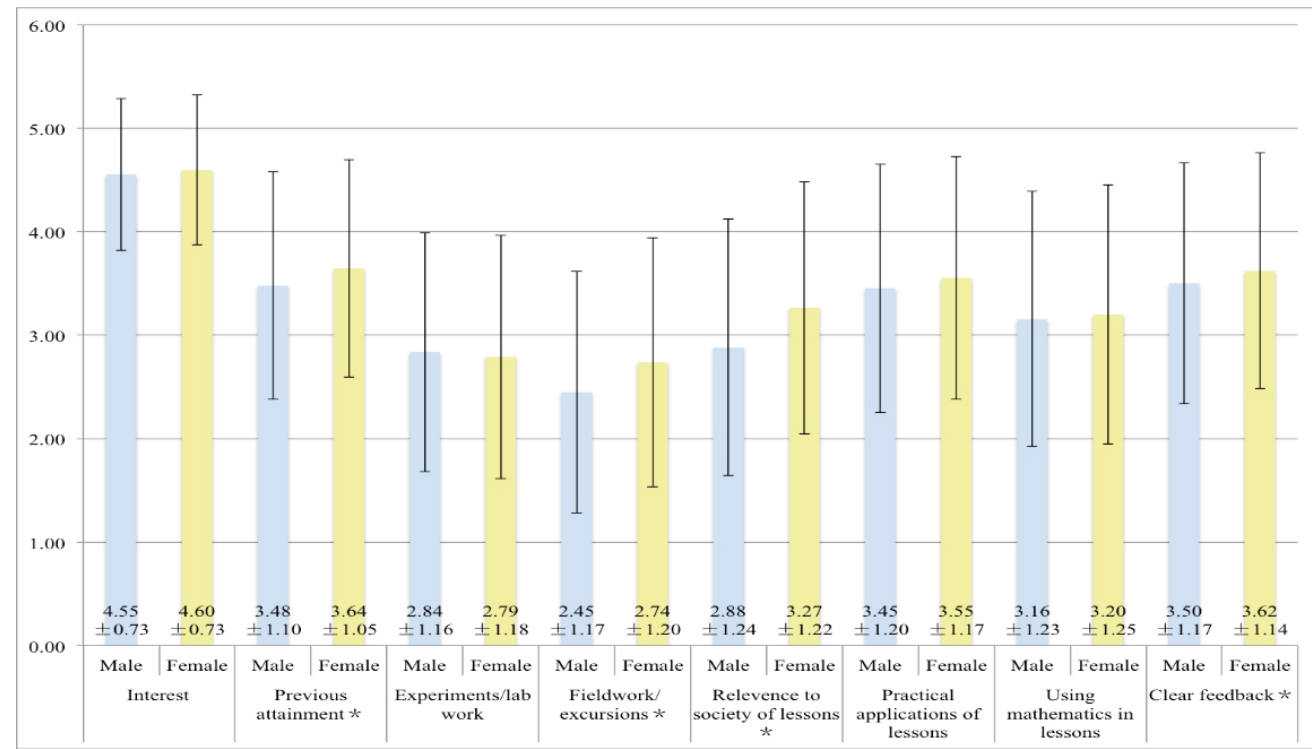

Figure 3. Results of formal learning experiences $(*, p<0.05)$.

\section{Informal learning experiences}

In informal educational settings, both male and female students considered watching popular science TV channels or programs such as Discovery channel most important for them as informal learning experiences. As shown in Figure 5, male students considered watching films or TV drama series as the least important experiences, while female students considered playing computer games least important. Significant gender differences were found in informal learning experiences, including reading science books or magazines, watching science fiction/films, playing computer games, and watching science TV channels/programs $(p<0.05)$. The females valued visiting museums/science centers and watching films/drama TV slightly higher than the males.

\section{Current Learning Experiences}

The second question examined students' responses to their current learning experiences, including to what degree they agreed with the statements about their current student life and how their current student life was going compared to their expectations. As shown in Figure 6 and 7, no significant gender difference was found in students' overall responses to their current learning experiences, including their current study life and study life compared to expectations. 


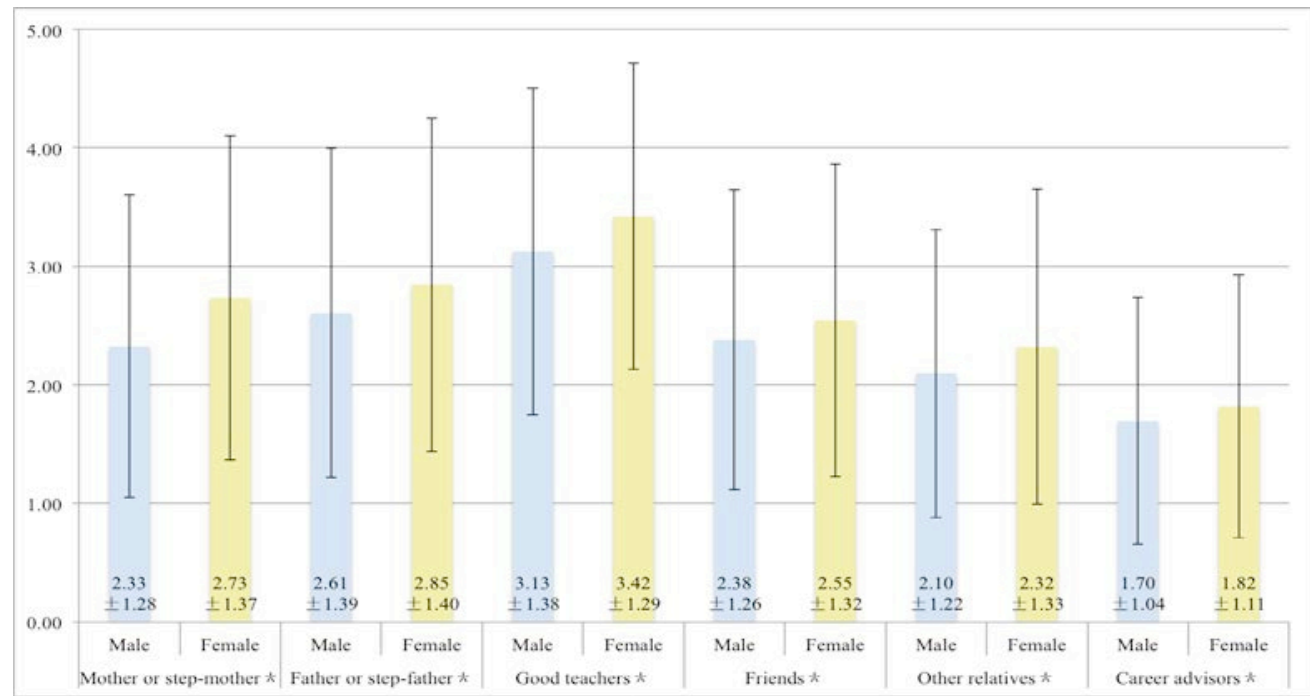

Figure 4. Results of social influence (*, $p<0.05)$.

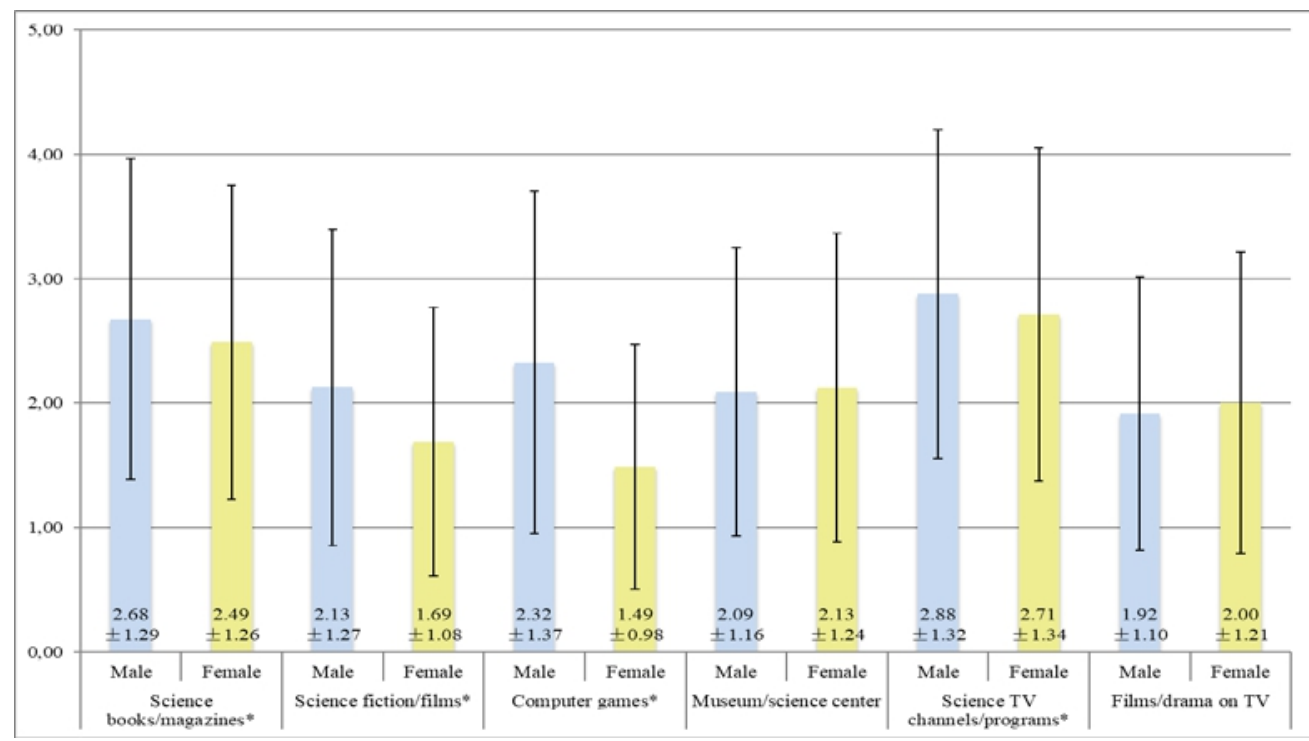

Figure 5. Results of informal learning experiences $(*, p<0.05)$. 


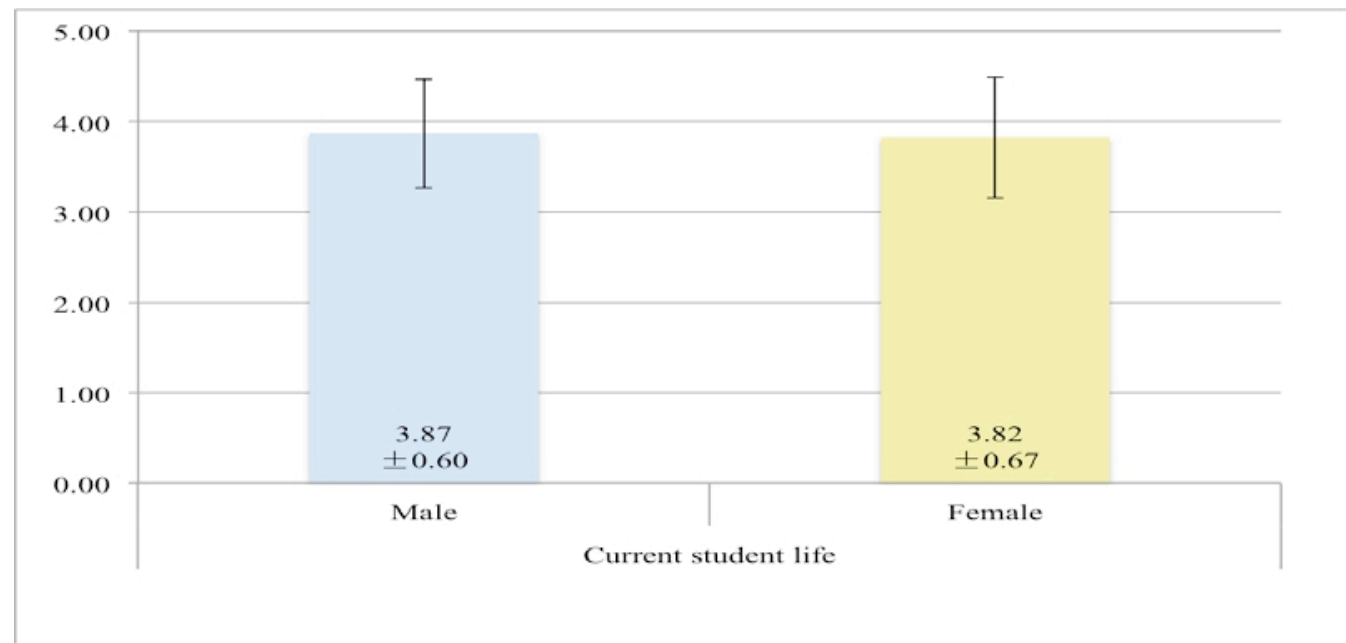

Figure6. Results of current student life.

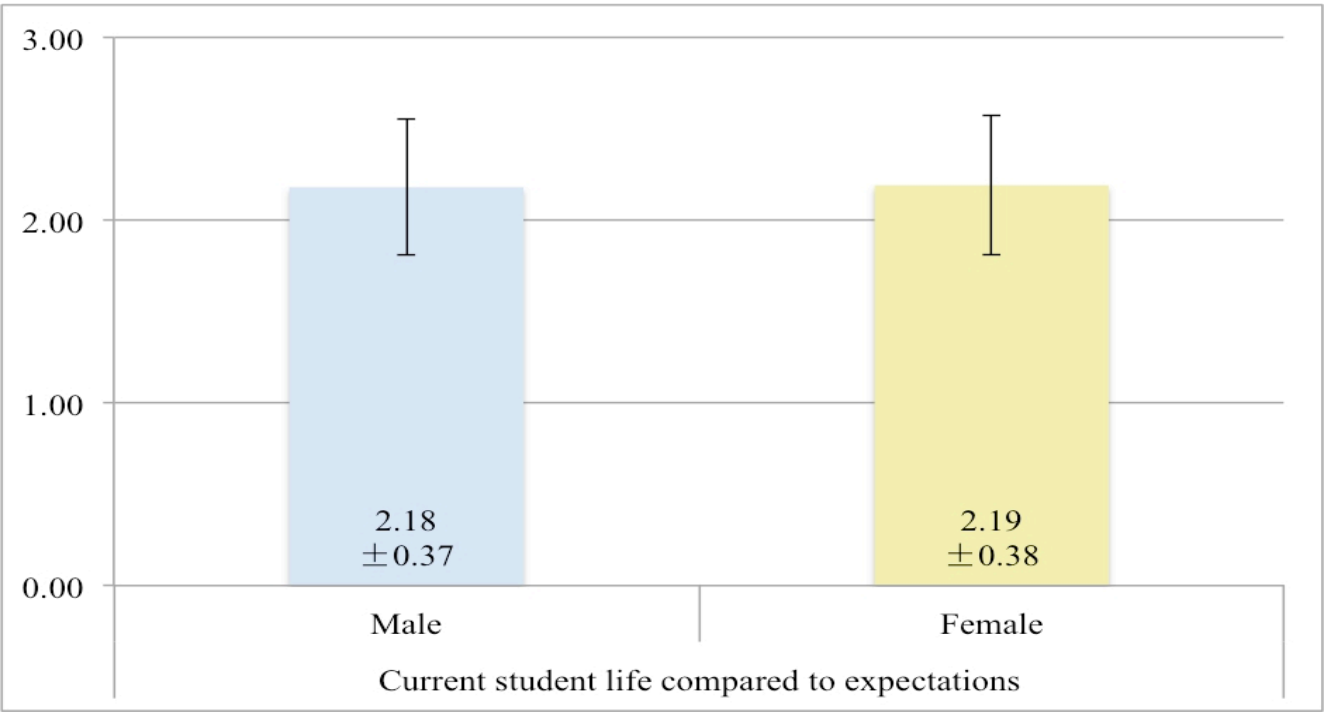

Figure 7. Results of current student life compared to expectations.

\section{Current student life}

When examining students' responses to statements describing their current student life in STEM majors, male and female students agreed on two aspects: what they enjoyed most was the company of other students; what they enjoyed least was lack of personal feedback from lecturers and teachers when they needed it. As shown in Figure 8, significant gender differences were found in statements regarding university working condition and the relevance of learning content $(p<0.05)$. The male students perceived better working conditions at universities than the females did, and the male students 
considered learning content to have greater relevance than did the female students.

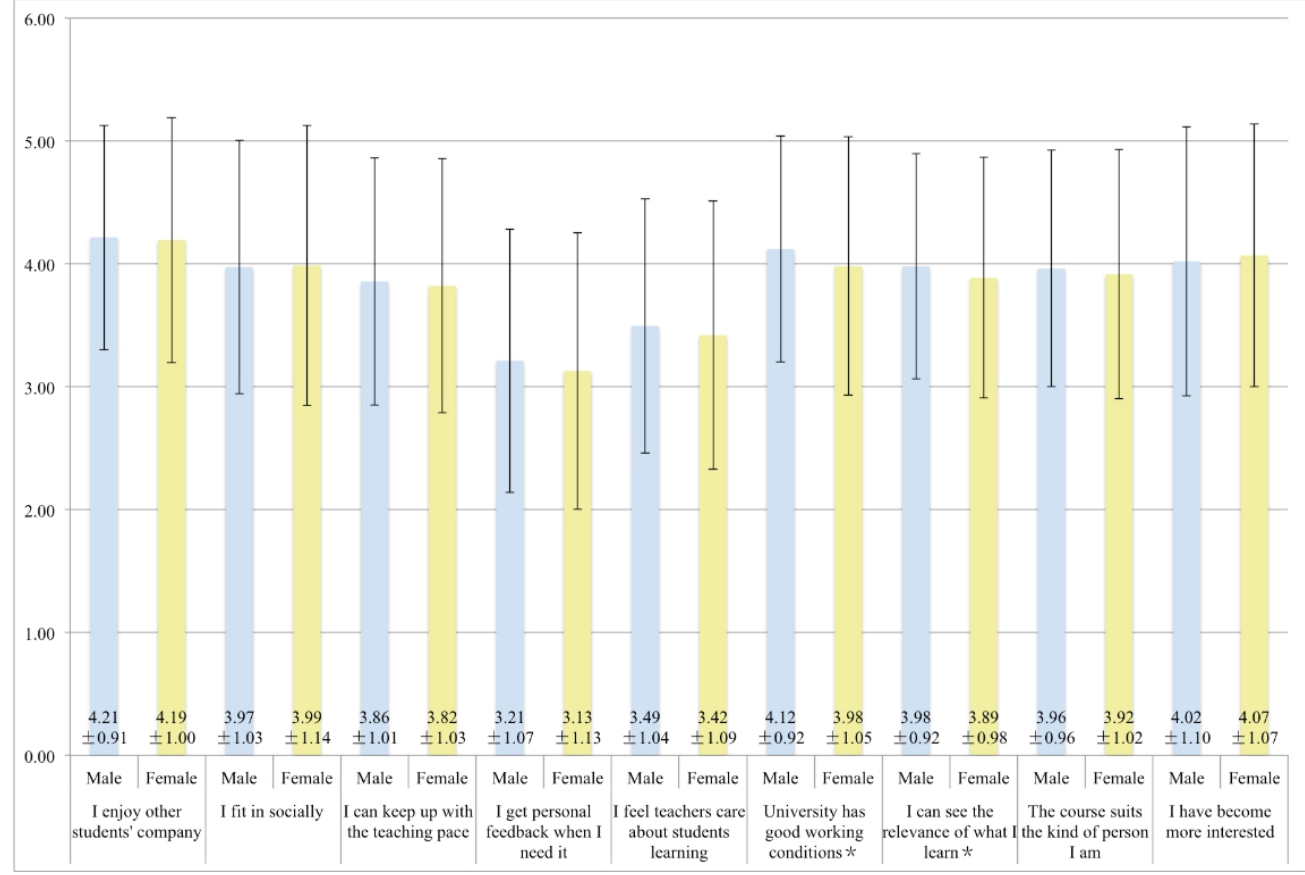

Figure 8. Results of current student life in aspects $(*, p<0.05)$.

\section{Current student life compared to expectations}

Both male and female students perceived current student life to be exceeding their expectations. Figure 9 illustrates that the overall experience of being a student on the course exceeded their expectations the most, while the quality of teaching exceeded their expectations the least. It was worth noting that both male and female students considered that they had to spend more effort on studying than they had expected, while female students reported slightly higher effort than their male peers did. A significant gender difference was found in the social relationship with fellow students as female students regarded this aspect of student life more positively than the male students did $(p<0.05)$.

\section{Self-efficacy Beliefs and Choice Goals}

The third research question concerned students' self-efficacy beliefs on the course and their intentions about persisting with STEM studies. As illustrated in Figure 10, a significant gender difference was found in male students expressing more confidence in their abilities and positive intentions about doing better in the future than female students did $(p<0.05)$. When looking into specific statements concerning self-efficacy beliefs, Figure 11 shows that male students expressed significantly higher self-efficacy beliefs 
than female students, believing themselves able to do better in the course, able to easily learn the subject matter and good enough in the course $(p<0.05)$. At the same time, both male and female students expressed a relatively low intention to leave the course before they finished.

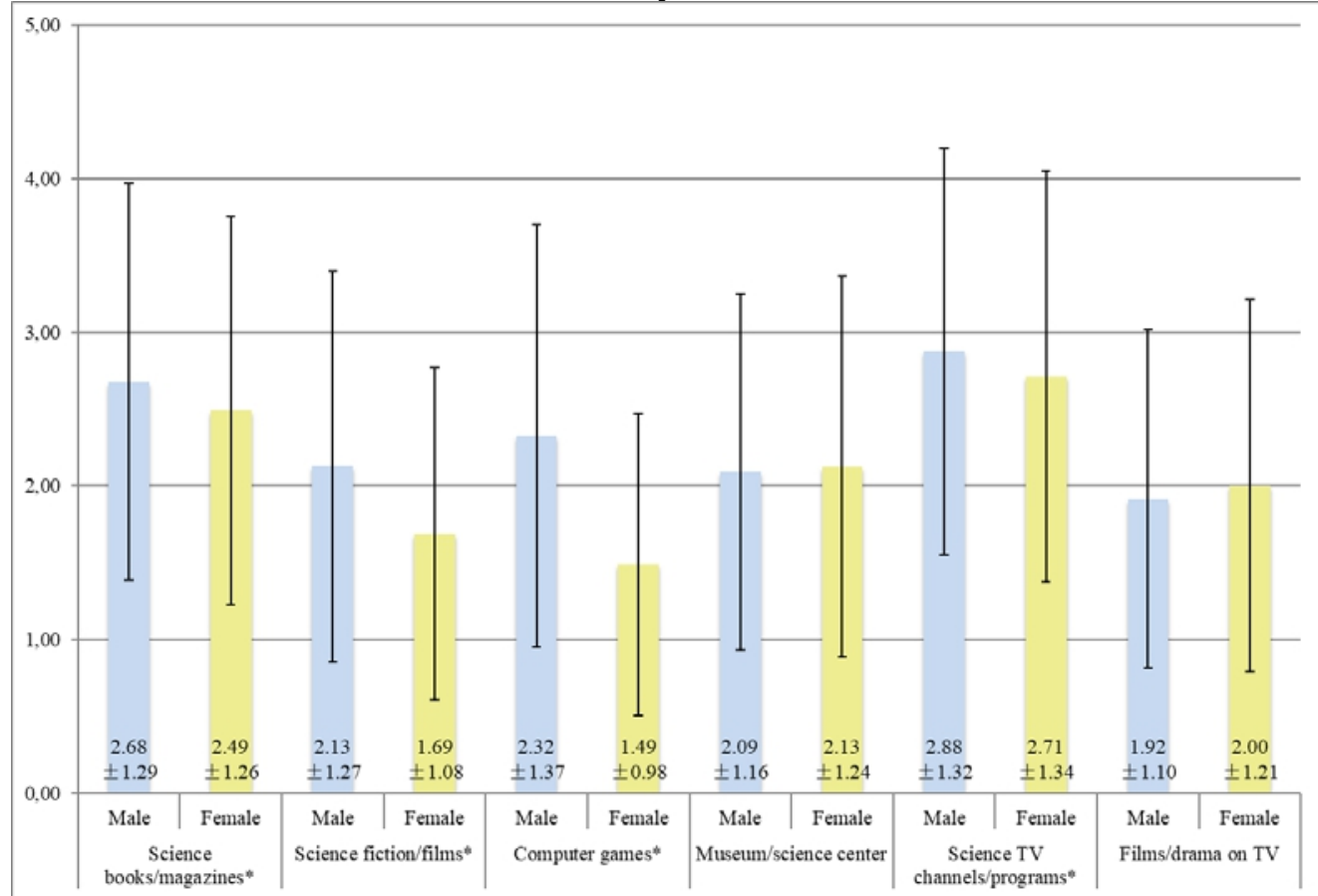

Figure 9. Results of current student life compared to expectations in aspects $(*, p<0.05)$.

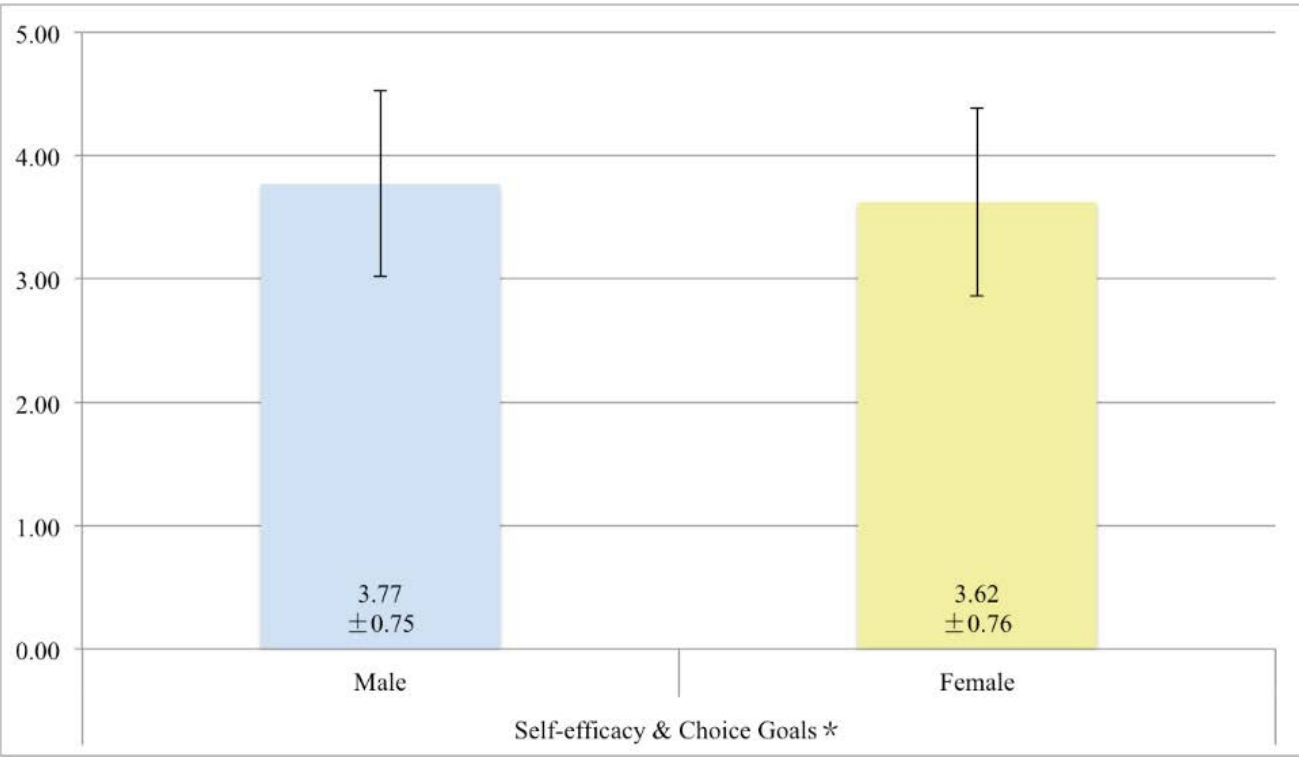

Figure 10 . Results of self-efficacy beliefs \& choice goals $(*, p<0.05)$. 


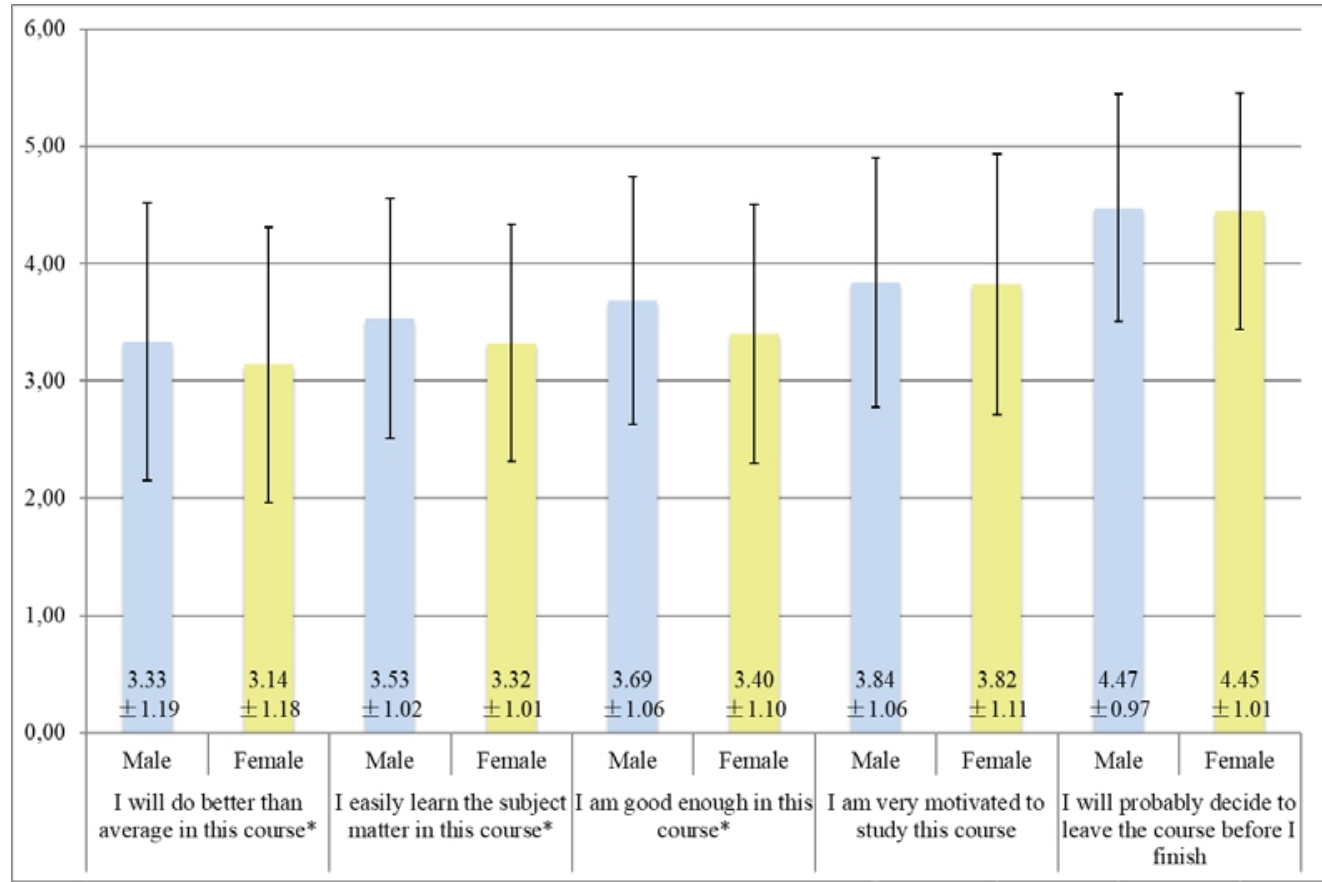

Figure 11. Results of self-efficacy beliefs $\&$ choice goals in aspects $(*, p<0.05)$.

\section{Discussions}

Results of this study complement various previous research studies in other geographic contexts. The following section explores different aspects of crucial learning experiences as well as important social and environmental impacts on students' academic choices that emerged from both the findings and the previous research. The discussion adopts a gender perspective as well as the application of SCCT.

\section{Learning Experiences in STEM}

This study shows that learning experiences in formal settings is pivotal to students' academic choices in STEM studies. Items examined in the IRIS questionnaire regarding formal learning experiences focused on direct engagement between students and their learning content. Formal learning experiences provided students with opportunities for developing mastery experiences in STEM related studies. Mastery experiences include math and science preparation in secondary school that play a critical role in developing students' self-efficacy beliefs and further influence their interest in pursuing STEM studies to an advanced level. Preparation includes the number of math and science courses taken, direct engagement in solving math problems or doing scientific experiments, and the attainment from these courses (Wang 2013). However, as Brandell et al. (2008) identified when examining the curriculum gap in math education during the transition from secondary 
education to higher education in Sweden, certain math constructs that students were expected to be familiar with in higher education, however, remained lacking in their secondary school curriculum. At the same time, students' direct participation in solving math problems such as constructing proofs, are largely limited in secondary level math classes, while these problem-solving skills are essential in higher education math. As Brandell et al. (2008) point out, the lack of proper preparation during secondary school leads to prolonged or unsuccessful studies or even causes students to quit their mathematics studies at tertiary level. For female students, inadequate early preparation in math and science courses is problematic, particularly resulting in low math achievement and decreasing the number of math courses taken, further limiting their potential to enter advanced-level math and science courses in higher education (Shapiro and Sax 2011).

Mastery experience can also occur in informal educational settings, such as doing scientific experiments in science centers. Activities that demonstrated significant differences in this study spoke to students' indirect engagement with their learning content, such as receiving STEM-related knowledge from TV programs, science books, or playing computer games. In this case, modeling as another source of self-efficacy beliefs, plays an important role in informal learning experiences. Certain role models that students observe in science books or TV programs can build on or impede their confidence in STEM fields. Self-identification with role models helps students form a social standard to reflect their own capabilities and aspirations to the competencies displayed by the proficient models (Bandura 1994). In this study, informal learning experiences played a more important role in the study choices of male students than female students. One explanation could be that young female students have fewer role models to emulate in informal learning settings simply because the majority of scientists and engineers across countries and cultures are currently men (Blickenstaff 2005). The low proportion of women in STEM-related disciplines sends a message to girls that these studies are unattractive and discourages them from developing an interest to participate.

\section{Self-efficacy and Interest in STEM}

Self-efficacy beliefs, especially math self-efficacy beliefs developed and strengthened from learning experiences, play a significant and positive role in shaping students' interests and further intent to engage in STEM studies (Wang 2013). Although the IRIS questionnaire did not explore students' math and science self-efficacy beliefs during pre-higher education, other studies have shown that male students are more self-efficacious in math than female students despite their comparable achievements (Eccles 1994; Pajares 2005; Watt 2006; as cited in Wang 2013). Similarly, Sax $(1994,2008)$ states that 
female students consistently express lower levels of academic and mathematical confidence than male peers even when they demonstrate equal academic and mathematical abilities (as cited in Shapiro et al. 2011). In other words, women may not enter or leave STEM disciplines because lack of academic ability, but rather because of the lack of academic self-efficacy beliefs (Brainard and Carlin 1998).

Blickenstaff (2005) points out that one of the most common reasons that girls gave to explain their interest in life sciences as opposed to physical science was their desire to care for people or animals, which was also regarded a "public relations" concern for science as a discipline. One key claim in science education, particularly in Physics and Chemistry, is that students in particular are insufficiently interested in not motivated to pursue science subjects because of the lack of perceived "relevance" of science for themselves and for the society in which they live and operate (Stuckey et al. 2013). The results of this study echoed this point that female students showed more concern about lesson content that shows the relevance of science to society. For women, having access to real-world applications of science may be particularly important in reinforcing their decision to pursue STEM disciplines (Shapiro et al. 2011). Their disregard of STEM as a vehicle for improving the human condition may discourage them from persisting with STEM. (Sax 1994, 2011; as cited in Shapiro et al. 2011). In order to keep students, especially female students, interested in and motivated to study science, it is of great importance to imbed the true importance of science in a technoscientific world as well as its related applications with regard to ecological, economical and societal development (Stuckey et al. 2013).

\section{Social Influence in STEM}

Social influence can be regarded as comprising two sources of selfefficacy beliefs (modeling and social persuasion) and important contextual factors as supports or barriers for students' academic choices in STEM disciplines. The results of this study show that female students regarded social influences on choosing STEM studies as more important than their male peers. At the same time, after they enrolled in STEM majors, female students valued the social aspects of learning experiences such as whether they enjoyed the company of other students or fitted in socially more than male students.

\section{Parental influence}

As for important social influences on and expectations for women to enter and retain STEM majors, Shapiro et al. (2011) emphasize the rolemodeling effect of parents. Having one or both parents in STEM careers increases the likelihood of both men and women pursuing STEM studies, specifically, having practical role models, and mentors are important for 
women due to the under-representation of professional women in STEM. Ferry et al. (2000) states that parental encouragement in math and science significantly influences learning experiences. However, Vetter (1996) argues that parental influence is not always positive. The gendered stereotypes of parents can lower educational expectations and aspirations for daughters and negatively affect their academic achievements (as cited in Shapiro et al. 2011). Science capital is defined as a conceptual device that combines various types of economic, social and cultural capital that specifically relate to science (Archer et al. 2014). These recourses related to science learning can either strengthen or weaken students' aspirations towards, and identifications with, science and science careers (Wong 2015). Having important family members in STEM disciplines is particularly important for students from underrepresented groups to aspire to science career and receive the additional resources to guide their pathways. Results showed that students with a family member working in a science-related job are 2.16 times more likely to develop a strong interest in and aspiration to science careers than those who do not (DeWitt and Archer 2015).

\section{Teachers and career advisors}

In this study, good teachers were found to have the most important social influence on students of both genders. Shapiro et al. (2011) point out that quality of teachers and pedagogy strongly influence students' interest and retention in STEM majors, especially women students. Female faculty members perceived as role models can likewise bolster women's interest in STEM (Ibid). However, teachers with sexist predispositions can foster a "chilly climate" in classrooms that discourage female participation in science and math classes in secondary education (Blickenstaff 2005). Warrington and Younger (2000) found that some science teachers still harbor sexist attitudes and different expectations for academic achievement of male and female science students, and they tend to be overly generous in predicting boys' science achievement while underestimating that of girls (noted by Blickenstaff 2005). In the higher education context, academic interaction between students and teaching faculty may help students better integrate into the college environment and assist them in better aligning their academic aspirations with actual choices (Wang 2013). This study showed that both male and female students were most unhappy about not receiving personal feedback from faculty members when they needed it. Not being able to receive help when needed increases both stress and the possibility of dropping out. On the other hand, the "chilly climate" also exists in higher education, especially in fields that are traditionally viewed as masculine disciplines, such as science and engineering. Some interactions between students and instructors have negative ramifications for students' interest and retention in STEM majors, particularly 
disadvantaging women (Hall and Sandler 1982; as cited in Shapiro et al. 2011). Poor teaching and lack of interest in the subject are often cited as reasons for leaving by female students who dropped a science or engineering track (Blickenstaff 2005).

\section{Peer influence and social culture}

Peer culture influences women's choices in and commitment to STEM disciplines both within and outside educational settings (Shapiro et al. 2011). The competitive environment fostered by STEM classroom pedagogies promotes an emphasis on individual success rather than on collaborative learning (Strenta et al. 1994; Astin and Sax 1996; Seymour and Hewitt 1997; as cited in Shapiro et al. 2011). In this study, both male and female students put high value on enjoying the company of other students in the course. Female students were more satisfied with these social relationships than their male peers were. However, Colbeck et al. (2001) suggest that peer interactions can result in greater "chilly climate" feelings for female students than they get from student-faculty interactions. Female engineering students are more likely to report different treatment from male students both in general and in collaborative learning situations. Cohoon (2001) reported that departments with a higher proportion of females such as computer science were more likely to retain those women at a rate comparable to men (as cited in Shapiro et al. 2011). Margolis et al. (2000) add that women often find the peer environment in STEM majors such as computer science unwelcoming. Interactions with male students can unravel women's confidence and make them feel that they are taken less seriously. Margolis et al. (2000) observed that male students make derogatory comments that may reinforce women's sense of not belonging, for example "You only got into computer science because you are a girl” (Ibid, p. 117). The influence of peer culture extends beyond classrooms. The friendships among high school girls influence their advanced-coursetaking patterns, particularly in math and science (Riegle-Crumb et al. 2006). Specifically, a combination of female friends and performance in math and science in friendship groups facilitate women's persistence in taking advanced courses such as calculus and physics. Peer interaction provides women with the environment to exchange information, find study partners, and create informal peer role models (Hyde and GessNewsome 2000; Kahveci et al. 2007; as cited in Shapiro et al. 2011).

\section{Conclusion}

The decision to pursue a STEM major, and later a related career, is a longitudinal process that builds during secondary education and carries on into postsecondary studies (Wang 2013). Thus, appreciating the combined effects and experiences of secondary and higher education levels is crucial to better 
understanding what shapes students' academic and career choices in STEM (Wang 2013). The SCCT choice model (Figure 1) shows how students' learning experiences in both formal and informal pre-higher education settings are influenced by person input (gender in this case) and background contextual affordances like science capital (socioeconomic status, social connections and cultural factors) in relation to STEM fields. Several factors and their various combinations influence the formation of interests in STEM fields through selfefficacy beliefs and outcome expectations: They include learning experiences (like science and math preparation at school) where one can acquire mastery experiences, modeling experiences (self-identification with role models in formal and informal education), and social persuasion from important social connections and anxiety. All of them encourage the student to choose STEM as subject in higher education. After entering STEM studies, students' current learning experiences, including social aspects (whether they fit into the program), teaching aspects (connection with faculty), university facilities (regarding research equipment), and stresses experienced during studies, directly impact the self-efficacy beliefs which mediate the formation of choice goals that determine whether they persist with or leave the program.

Contextual factors from the environment exert influence on the process of academic choice making. SCCT categorizes distal and proximal contextual factors according to the relative proximity of these influences on the academic/career choice making. This study has found that environmental factors such as social connections are particularly important for women. On the other hand, more proximal factors such as the competitive environment of STEM studies, the "chilly climate" female students perceive, and the stress they experience during studies are more likely to make them less confident in their STEM abilities and thus increase the potential for dropping out of STEM disciplines and careers. As was suggested earlier, a longitudinal study would update our understanding of the current situation, while more qualitative research would contribute depth to the analysis.

\section{References:}

1. Anastasiadou, S. D., Angeletos, T., \& Vandikas, I. (2010). A Multidimensional Statistical Analysis of Students' Attitudes toward Physics: The Case of 11th Grade Students of First-generation Immigrants in Greece. International Journal of Diversity in Organisations, Communities \& Nations, 10(1).

2. Archer, L., DeWitt, J., \& Willis, B. (2014). Adolescent boys' science aspirations: Masculinity capital, and power. Journal of Research in Science Teaching, 51(1), 1-30. 
3. Bandura, A. (1986). Social foundations of thought and action: A social cognitive theory. Englewood Cliffs, NJ: Prentice-Hall.

4. Bandura, A. (1994). Self-efficacy. In V. S. Ramachaudran (Ed.), Encyclopedia of human behavior (Vol. 4, pp. 71-81). New York: Academic Press. (Reprinted in H. Friedman [Ed.], Encyclopedia of mental health. San Diego: Academic Press, 1998).

5. Blickenstaff, C. J. (2005). Women and science careers: leaky pipeline or gender filter? Gender and Education, 17(4), 369-386.

6. Brainard, S. G., \& Carlin, L. (1998). A Six-Year Longitudinal Study of Undergraduate Women in Engineering and Science. Journal of Engineering Education, 87(4), 17-27.

7. Brandell, G., Hemmi, K., \& Thunberg, H. (2008). The widening gap A Swedish perspective. Mathematics Education Research Journal, 20(2), 38-56.

8. Bryman, A. (2016). Social research methods. New York: Oxford University Press.

9. Byars-Winston, A., Estrada, Y., Howard, C., Davis, D., \& Zalapa, J. (2010). Influence of social cognitive and ethnic variables on academic goals of underrepresented students in science and engineering: A multiple-groups analysis. Journal of Counseling Psychology, 57(2), 205-218. https://doi.org/10.1037/a0018608.

10. Colbeck, C. L., Cabrera, A. F., \& Terenzini, P. T. (2001). Learning Professional Confidence: Linking Teaching Practices, Students' SelfPerceptions, and Gender.” Review of Higher Education, 24(2), 173191.

11. DeWitt, J., \& Archer, L. (2015). Who Aspires to a Science Career? A comparison of survey responses from primary and secondary school students. International Journal of Science Education, 37(13), 21702192. https://doi.org/10.1080/09500693.2015.1071899.

12. DeWitt, J., \& Archer, L. (2017). Participation in informal science learning experiences: the rich get richer? International Journal of Science Education, Part B, 7(4), 356-373. https://doi.org/10.1080/21548455.2017.1360531.

13. DeWitt, J., Archer, L., Osborne, J., Dillon, J., Willis, B., \& Wong, B. (2011). High aspirations but low progression: the science aspirationscareers paradox amongst minority ethnic students. International Journal of Science and Mathematics Education, 9(2), 243-271.

14. Elster, D. (2014). First-Year Students' Priorities and Choices in STEM Studies-IRIS Findings from Germany and Austria. Science Education International, 25(1), 52-59.

15. European Commission. (2018). Commission staff working document: Proposal for a council recommendation on Key Competences for 
lifelong learning. Resource document. https://ec.europa.eu/education/sites/education/files/swdrecommendation-key-competences-lifelong-learning.pdf. Accessed 14 March 2018.

16. Ferry, T. R., Fouad, N. A., \& Smith, P. L. (2000). The Role of Family Context in a Social Cognitive Model for Career-Related Choice Behavior: A Math and Science Perspective. Journal of Vocational Behavior, 57(3), 348-364. https://doi.org/10.1006/jvbe.1999.1743

17. Goan, S., Cunningham, A., and Carroll, C. (2006). Degree Completions in Areas of National Need, 1996-97 and 2001-02. Resource document. Washington, D.C.: National Center for Education Statistics, 2006. https://nces.ed.gov/pubs2006/2006154.pdf. Accessed 14 March 2018.

18. Hansen, J. C. (1984). The measurement of vocational interests: Issues and future directions. In S. D. Brown \& R. W. Lent (Eds.), Handbook of counseling psychology (pp. 99-136). New York: Wiley.

19. Hazelkorn, E., Ryan, C., Beernaert, Y., Constantinou, C. P., Deca, L., Grangeat, M., Welzel-Breuer, M. (2015). Science Education for Responsible Citizenship: Report to the European Commission of the Expert Group on Science Education. Luxembourg: Publications Office of the European Union.

20. Heilbronner, N. (2011). Stepping Onto the STEM Pathway: Factors Affecting Talented Students' Declaration of STEM Majors in College. Journal for the Education of the Gifted, 34(6), 876-899. https://doi.org/10.1177/0162353211425100.

21. Henriksen, E., Dillon, J., \& Ryder, J. (2014) Understanding student participation and choice in science and technology education. Dordrecht: Springer.

22. Hossain, M. (2012). How to motivate US students to pursue STEM (science, technology, engineering and mathematics) careers. US-China Education Review. A. 4(2012) 442-451.

23. IRIS. (2008). Annex I: Description of work. Resource document. http://www.iris.v-izdelavi.si/data/upload/IRIS_annex1_nov6th_1.pdf. Accessed 17 March 2018.

24. IRIS. (2010). IRIS working document 2.2: Guidelines for IRIS $Q$ translation, sampling, data collection and coding. Resource document. http://www.iris.v-izdelavi.si/iris-documents/. Accessed 17 March 2018.

25. IRIS. (2012). Published Summary. Resource document. http://www.mn.uio.no/fysikk/english/research/projects/iris/iris_publis hable_summary.pdf. Accessed 17 March 2018. 
26. Jidesjö, A., Danielsson, Å., \& Björn, A. (2015). Interest and Recruitment in Science: A Reform, Gender and Experience Perspective. Procedia - Social and Behavioral Sciences, 167, 211-216. https://doi.org/10.1016/j.sbspro.2014.12.664.

27. Kim, M., \& Dopico, E. (2016). Science education through informal education. Cultural Studies of Science Education, 11(2), 439-445. https://doi.org/10.1007/s11422-014-9639-3.

28. Langen, A. van, \& Dekkers, H. (2005). Cross-national differences in participating in tertiary science, technology, engineering and mathematics education. Comparative Education, 41(3), 329-350. https://doi.org/10.1080/03050060500211708.

29. Laerd statistics. (n.d.). SPSS statistics tutorials and statistical guides. Resource document. https://statistics.laerd.com/statisticalguides/independent-t-test-statistical-guide.php. Accessed 25 April 2018.

30. Laugksch, R. C. (2000). Scientific literacy: A conceptual overview. Science Education, 84(1), 71 -94.

31. Lent, R. W., Brown, S. D., \& Hackett, G. (1994). Toward a unifying social cognitive theory of career and academic interest, choice, and performance. Journal of Vocational Behavior, 45(1), 79-122.

32. Lent, R. W., Brown, S. D., \& Hackett, G. (2000). Contextual supports and barriers to career choice: a social cognitive analysis. Journal of counseling psychology, 47(1), 36-49.

33. Lent, R. W., Lopez, A. M., Lopez, F. G., \& Sheu, H.-B. (2008). Social cognitive career theory and the prediction of interests and choice goals in the computing disciplines. Journal of Vocational Behavior, 73(1), 52-62. https://doi.org/10.1016/j.jvb.2008.01.002.

34. Lopez, F. G., \& Lent, R. W. (1992). Sources of math self-efficacy in high school students. Career Development Quarterly, 41, 3-12.

35. Maltese, A. V., \& Tai, R. H. (2011). Pipeline persistence: Examining the association of educational experiences with earned degrees in STEM among U.S. students. Science Education, 95(5), 877-907.

36. Margolis, J., Fisher, A., \& Miller, F. (2000). The anatomy of interest: Women in undergraduate computer science. Women's Studies Quarterly, 28(1/2), 104-127.

37. Navarro, M., Förster, C., González, C., \& González-Pose, P. (2016). Attitudes toward science: measurement and psychometric properties of the Test of Science-Related Attitudes for its use in Spanish-speaking classrooms. International Journal of Science Education, 38(9), 14591482. 
38. OECD. (2017). Education at a glance. Resource document. https://read.oecd-ilibrary.org/education/education-at-a-glance2017_eag-2017-en\#page1. Accessed 25 April 2018.

39. OECD.stat. (n.d.). Enrollment by field - Sweden. Resource document. http://stats.oecd.org/Index.aspx?DatasetCode=RGRADSTY Accessed 25 April 2018.

40. Pallant, J. (2016). SPSS survival manual: a step by step guide to data analysis using SPSS. Maidenhead: Open University Press/McGrawHill.

41. Perry, B. L., Link, T., Boelter, C., \& Leukefeld, C. (2012). Blinded to science: gender differences in the effects of race, ethnicity, and socioeconomic status on academic and science attitudes among sixth graders. Gender and Education, 24(7), 725-743.

42. Riegle-Crumb, C., Farkas, G., and Muller, C. (2006). The Role of Gender and Friendship in Advanced Course Taking. Sociology of Education, 79(3), 206-228.

43. Sadler, P. M., Sonnert, G., Hazari, Z., \& Tai, R. (2012). Stability and volatility of STEM career interest in high school: A gender study. Science Education, 96(3), 411-427.

44. Shapiro, C. A., \& Sax, L. J. (2011). Major selection and persistence for women in STEM. New Directions for Institutional Research, 2011(152), 5-18. https://doi.org/10.1002/ir.404.

45. Skolverket. (2000). Descriptive data on childcare and schools in Sweden in 2000. Stockholm: National Agency for Education.

46. Sosniak, L. A. (1985). Becoming an outstanding research neurologist. In B. S. Bloom (Ed.), Developing talent in young people (pp. 348-408). New York, NY: Ballantine.

47. Stuckey, M., Hofstein, A., Mamlok-Naaman, R., \& Eilks, I. (2013). The meaning of "relevance" in science education and its implications for the science curriculum. Studies in Science Education, 49(1), 1-34. https://doi.org/10.1080/03057267.2013.802463.

48. Subotnik, R., \& Steiner, C. (1993). Adult manifestations of adolescent talent in science. Roeper Review, 15, 164-169.

49. Tyson,W., Lee, R., Borman, K. M., \& Hanson, M. A. (2007). Science, technology, engineering, and mathematics (STEM) pathways: High school science and math coursework and postsecondary degree attainment. Journal of Education for Students Placed at Risk, 12(3), 243-270.

50. Tytler, R., \& Osborne, J. (2012). Student Attitudes and Aspirations Towards Science. In B. J. Fraser, K. Tobin, \& C. J. McRobbie (Eds.), Second International Handbook of Science Education (pp. 597-625). Dordrecht: Springer Netherlands. 
51. UNDP. (2015). Human Development Report-Sweden. Resource document. http://hdr.undp.org/en/countries/profiles/SWE. Accessed 30 April 2018.

52. Wang, X. (2013). Why Students Choose STEM Majors: Motivation, High School Learning, and Postsecondary Context of Support. American Educational Research Journal, 50(5), 1081-1121. https://doi.org/10.3102/0002831213488622.

53. Wong, B. (2012). Identifying with Science: A case study of two 13year-old "high achieving working class" British Asian girls. International Journal of Science Education, 34(1), 43-65. https://doi.org/10.1002/tea.21231.

54. Wong, B. (2015). Careers "From" but not "in" science: Why are aspirations to be a scientist challenging for minority ethnic students?: CAREERS “FROM” BUT NOT “IN" SCIENCE. Journal of Research in Science Teaching, 52(7), 979-1002 